\title{
The best model of care for children and young people with diabetes
}

\author{
S Williamson \\ Consultant Paediatrician, Department of Paediatrics, Ayrshire and Arran NHS, UK
}

\begin{abstract}
The health service is challenged with finding the best way of caring for increasing numbers of children and young people with diabetes with an increasingly intensive approach to their condition. Drawing on studies comparing outcomes across paediatric diabetes centres across the world, this paper examines what works best. Using the framework of the chronic care model, a theoretical best model of care is constructed from a combination of effective structures and processes of care. The model consists of patient-focused, goalbased care provided by a multidisciplinary team of skilled professionals. These local teams should be able to provide all aspects of diabetes care, from social and mental health care to the provision of accepted modern technologies, such as insulin pumps. Robust audit data need to be available from fully supported IT systems measuring structures, processes and outcomes of care. A central organisation such as a managed clinical network should exist to co-ordinate and supervise the delivery of this model in order to ensure equal delivery of high quality care for all.
\end{abstract}

\author{
Correspondence to S Williamson, \\ Department of Paediatrics, \\ Ayrshire and Arran NHS, 3 Lister \\ Street, Crosshouse Hospital, \\ Kilmarnock KA2 OBE, UK
} scott.williamson@nhs.net doi:I0.4997/JRCPE.20I0.S04

\section{DECLARATION OF INTERESTS No conflict of interests declared.}

\section{INTRODUCTION}

The incidence of diabetes in childhood has been rising by $3.9 \%$ each year in Europe in recent years.' This has been higher in the pre-school age group, where the incidence is predicted to double by 2020 from its 2005 figure.' Young people (defined as individuals between the ages of II and I 8 years ${ }^{2}$ ) with diabetes struggle to attain the standards for glycaemic control set for them., ${ }^{3,4}$ They have a high mortality, ${ }^{5}$ develop long-term complications at a relatively early age ${ }^{6}$ and have high rates of mental health problems. ${ }^{7}$ These factors challenge health services to find the best way of caring for increasing numbers of children and young people with diabetes, so the best model of care needs to be clearly defined. This paper summarises the available evidence and expert opinion on the factors that may contribute to the best model of care for children and young people with diabetes.

\section{What is a 'model of care'?}

A clear definition of 'model of care' is hard to find in the medical literature. Examples include: 'an overarching design for the provision of a particular type of health care service that is shaped by a theoretical basis, evidence based practice and defined standards' ${ }^{\text {' }}$ and 'a multifaceted concept, which broadly defines the way health services are delivered'. 'The main theme of these definitions is the provision, or delivery, of healthcare. Delivery of healthcare has three components: structure, process and outcome. ${ }^{10}$ Structural data are characteristics of personnel and hospitals or clinics. With these a framework is created from which to deliver the process. Process data are the components of the encounter between a doctor or another healthcare professional and a patient (e.g.teaching carbohydrate counting or using a particular insulin regime). The process is intended to create a beneficial effect on outcomes. Outcome data refer to the patient's subsequent health status (e.g. glycosylated haemoglobin, $\mathrm{HbA}_{\mathrm{lc}}$, or frequency of hypoglycaemia).

A simple definition of the term 'model of care' would therefore be: 'The structures of healthcare and the processes they deliver.'

\section{What models of care are used for childhood diabetes?}

In the UK, children with diabetes in the most part have their care delivered by specific professionals based within secondary care." This has been directed by consensus agreements such as the St Vincent declaration and the recommendations of the British Paediatric Association in 1990, ${ }^{12,13}$ but it relies on the structures underpinning the secondary healthcare services, which are not specifically designed for chronic care so may have a number of shortcomings. Models of care for childhood diabetes have evolved slowly from this by adopting novel 'processes' into slowly adapting structures (e.g. implementing intensive insulin therapy, then slowly increasing the numbers of nursing staff available to deliver it), rather than making radical changes to structures to enable the most efficient delivery of the process. We therefore do not find radically different models of care for childhood diabetes within the UK and across the world.

\section{Which factors contribute to better care?}

Several studies have compared cohorts of children in different diabetes centres over time and have attempted to speculate on which aspects of the most successful 
SWilliamson

centres could contribute to a best model of care. They have used $\mathrm{HbA}_{\mathrm{lc}}$ as the outcome measure as it is the best known predictor of long-term complications as outlined in the Diabetes Control and Complications Trial (DCCT) ${ }^{14}$ and so is assumed to be a measure of successful delivery of care in the real world (as opposed to that within a clinical trial).

The Hvidøre study group studied a cohort of 2,873 children with type I diabetes in 22 centres in 18 countries across Europe, Japan and North America in 1995 and found that average $\mathrm{HbA}_{\mathrm{lc}}$ varied significantly between centres from 7.6 to $10.2 \%{ }^{15}$ The centres were reassessed three years later. Although many had adopted an intensive insulin regime after the first analysis, significant differences in $\mathrm{HbA}_{\mathrm{Ic}}$ still existed. These differences were not accounted for by differences in genetics, ethnicity, insulin regime or rates of hypoglycaemia, suggesting that it was the delivery of care in some centres which was better than others. The authors concluded that diabetes education, management from the onset of the disease, different attitudes within diabetes teams and different levels of patient empowerment were the factors explaining the differences. ${ }^{16}$

Likewise, the Diabaud 2 study found significant differences in $\mathrm{HbA}_{\mathrm{Ic}}$ between 18 Scottish paediatric diabetes centres, also suggesting that care in some centres was better than others. ${ }^{17}$ Deployment of resources, organisation of the clinic and strategies of medical care were suggested as possible reasons for the differences, but these factors could not be quantified by the study. Cultural factors have also been suggested as a significant factor affecting outcomes between centres. A comparison of a centre in Scotland (Dundee) and a centre in Italy (Chietti) found significant differences in their mean $\mathrm{HbA}_{\mathrm{lc}}(9.1 \%$ vs $7.6 \%$, and the authors investigated possible cultural reasons for the differences by analysing interviews with children and young people. ${ }^{18}$ The cultural factors influencing glycaemic control appear to be communication, reciprocal support between young people and professionals, and family structure.

A cohort in Western Australia of 1,335 children prospectively followed up for 10 years from 1992 showed a significant improvement in overall $\mathrm{HbA}_{\mathrm{Ic}}{ }^{19}$ The authors speculated that the improvement may partly have been due to increased skills in the clinicians and caregivers, implying that the overall quality of care had improved during this time. A recent study of 2,705 children in the 19 diabetes centres in Denmark reported a significant decrease in $\mathrm{HbA}_{\mathrm{lc}}$ levels from 1996 to 2006 as well as a significant difference in $\mathrm{HbA}_{\mathrm{lc}}$ levels between centres. The reduction in $\mathrm{HbA}_{\mathrm{lc}}$ was related to increased self-monitoring of blood glucose, although there was no association with the number or type of insulin injections. ${ }^{20}$ The authors speculated that an increased focus on treatment goals, treatment regimens, glucose monitoring and optimal care may have contributed to the improvement.
TABLE I Facets of diabetes care delivery thought to affect outcomes in children and young people $e^{16-20,22,23}$

\begin{tabular}{|l|}
\hline Focus on education \\
\hline Management from the onset of the disease \\
\hline Attitudes of clinic personnel \\
\hline Patient empowerment \\
\hline Organisation of the clinic \\
\hline Strategies of medical care \\
\hline Communication \\
\hline Reciprocal support between young people and professionals \\
\hline Increased skills in clinicians and caregivers \\
\hline Treatment goals \\
\hline Focus on treatment regimes \\
\hline Glucose monitoring \\
\hline Frequent clinic visits and frequent telephone contact \\
\hline
\end{tabular}

These five studies have suggested some 'real world' evidence of factors within some centres that contribute to better outcomes. This is not strong evidence and many of these factors are vague and not well defined. However, each study has powerfully highlighted that it is not the treatments per se which make a difference to children in the real world, but other factors relating to healthcare delivery. As Ed Wagner of the MacColl Institute states:

Improvements in the quality of chronic illness care require more than evidence about efficacious tests and treatments. They also require evidence about the system changes that produce better care and quality improvement methods to implement such changes. ${ }^{21}$

Facets of diabetes care delivery thought to affect outcomes in children and young people are listed in Table I.

\section{THE CHRONIC CARE MODEL}

The MacColl Institute for Healthcare Innovation is a US think-tank which has developed a validated, evidence-based model of care for chronic disease..$^{24}$ It has identified six key elements of its chronic care model (CCM) (see Table 2). ${ }^{21}$

By considering all these elements, many centres in other fields of medicine have improved the quality of their healthcare ${ }^{25}$ and the model has been adapted for use

TABLE 2 The key elements of the chronic care model ${ }^{2}$

\begin{tabular}{|l|}
\hline I. Delivery system redesign \\
\hline 2. Decision support \\
\hline 3. Self-management support \\
\hline 4. Healthcare organisation \\
\hline 5. Community resources \\
\hline 6. Clinical information systems \\
\hline
\end{tabular}


internationally by the World Health Organization. ${ }^{26}$ To create the best model of care for childhood diabetes we should consider what evidence there is for the structures and processes we use in each of these six elements. The aforementioned cohort studies have given useful suggestions. Additional evidence for best practice in childhood and adolescent diabetes has been summarised in several recent evidence-based reports on the subject from Australia, ${ }^{27}$ the US (American Diabetes Association recommendations), ${ }^{28}$ the UK (National Institute for Health and Clinical Excellence, NICE, ${ }^{2}$ and Scottish Intercollegiate Guidelines Network, SIGN, ${ }^{29}$ guidelines), Canada (Canadian Diabetes Association recommendations) ${ }^{30}$ and the International Society for Paediatric and Adolescent Diabetes (ISPAD) ${ }^{22}$ consensus guidelines. These guidelines have been produced to give a comprehensive evaluation of the evidence for diabetes treatments and provide a basis for national standards. The recommendations from these guidelines can therefore be placed within the context of the CCM to help us to construct the best model of care for childhood diabetes.

\section{DELIVERY SYSTEM REDESIGN}

This element of the CCM concerns the delivery of effective and efficient clinical care.

\section{Team structure and centre size}

Since the St Vincent Declaration ${ }^{12}$ and the British Paediatric Association recommendations in $1990^{13}$ it has been accepted that children with diabetes should have their care provided by a local multidisciplinary team. All of the consensus guidelines specify that an integrated package of care should be delivered by a multidisciplinary team, appropriately trained and comprising of a consultant paediatrician or paediatric endocrinologist with an interest and expertise in diabetes, a specialist nurse, a dietician and a psychologist or social worker. ${ }^{2,22,23,27-30}$

From the guidelines and the available evidence it is difficult to define exactly how many patients an individual team should be responsible for, and how many professionals there should be in each team. There is evidence from the UK that children attending larger clinics with more specialised consultants receive better care, ${ }^{31,32}$ although a comparison of 207 paediatric diabetes centres in Germany and Austria did not reveal an effect of centre size on $\mathrm{HbA}_{\mathrm{lc}}$ when comparing centres with less than 50 patients to those with more than 50 patients. ${ }^{33}$ Within the UK, the Royal College of Nursing (RCN) recommends a ratio of diabetes specialist nurse to patient of one to no more than 70 children or young people based on their responsibilities and workload. ${ }^{34}$

Although specific recommendations for the ratio of dieticians and psychologists to patients are not available, it is clear from the consensus statements that these professionals are an essential component of each multidisciplinary team. Given the amount of evidence which exists on the effect of psychosocial factors on a child's diabetes control, the UK NICE guidelines recommend that all children and young people and their families have easy access to mental health workers. ${ }^{2}$ Likewise, with increasing use of intensive insulin therapy and insulin pumps in children comes an increasing need for access to expert dietetic advice. Given the complexity of the advice required, specialist paediatric dieticians with experience in childhood diabetes should be part of each team and available at each clinic. ${ }^{32,35}$

It is also recommended that advice from the team should be accessible 24 hours a day, by telephone., ${ }^{2,2230}$ The structure of care delivery should allow any child suspected of having diabetes to be referred without delay to the team. ${ }^{2}$

\section{Ambulatory care}

All six consensus guidelines suggest that, if appropriately resourced, a diabetes team should be able to offer homebased care from diagnosis if the child is well, ${ }^{2,22,23,27-30}$ although evidence supporting one of these processes over the other is inconclusive. ${ }^{36}$

Facilities should be in place to test $\mathrm{HbA}_{\mathrm{lc}}$ levels two to four times per year and this should be available in the clinic.,27

\section{How often does a child need to be seen?}

Children who are irregular in attendance are more likely to have acute complications of their diabetes and poor glycaemic control. ${ }^{37}$ Frequent clinic visits (3-4 per year) appear to be beneficial and predictive of improved clinical outcome. ${ }^{38} \mathrm{~A}$ trial which included measures to increase children's attendance at clinic found that by increasing attendance (mean of 7.1 visits in 24 months compared to control group of 5.2 visits), $\mathrm{HbA}_{\mathrm{lc}}$ and acute complications were reduced. ${ }^{39}$ The DCCT also showed similar improvements in the patients in the intensive therapy arm, who were reviewed on a monthly basis, as well as having frequent telephone contact. ${ }^{14}$ This degree of follow-up contact is not found in the consensus recommendations. Quarterly clinic visits are the recommendation within the $\mathrm{NICE}^{2}$ and ISPAD ${ }^{22}$ guidelines.

\section{DECISION SUPPORT}

This element of the CCM concerns the promotion of clinical care that is consistent with scientific evidence and patient preferences.

\section{Using evidence-based guidelines}

Patients should be aware of the team's use of standards and evidence-based guidelines. Literature is available from guideline publishers specifically for the public so they will have an expectation of the standards that the team is working towards. ${ }^{40}$ 
SWilliamson

\section{Screening for complications and associated conditions}

Screening should take place for long-term complications (retinopathy, nephropathy, foot exam) and associated conditions (coeliac disease, thyroid disease) as per the nationally accepted guidelines. Resources should be allocated to enable full implementation of screening guidelines. There are minor variations in the recommended screening frequency and age of testing across the world. 222,23,27-30 However, whichever guideline is accepted, the delivery of that process should be monitored carefully. The national diabetes audit in England and Wales is an example of a means of monitoring how good centres are at meeting the recommendations for screening by NICE. ${ }^{4}$ The diabetes team should have easy access to podiatry and ophthalmology services when required.

\section{Delivery of education}

The 2004 NICE guidelines stress the importance of the diabetes team delivering educational interventions which are structured and help the child or young person and parent develop their ability to decide on aspects of their own care. ${ }^{2}$ They also stress the importance of offering specific support strategies, such as mentoring and selfmonitoring of blood glucose levels supported by problem solving, to improve their self-esteem and glycaemic control. The evidence for this is still evolving. The five-day dose adjustment for normal eating (DAFNE) course teaches adults the principles of carbohydrate counting and dose adjustments. Evaluation revealed improved $\mathrm{HbA}_{\mathrm{lc}}$ and quality of life. ${ }^{41}$ Similar results have been reported from other standalone courses. ${ }^{42,43}$ Evidence for the use of such a course in children and young people is lacking, although in the UK the current KICk-OFF (Kids In Control OF Food) trial aims to provide this. ${ }^{44}$

As children become young people and then young adults, they should be motivated to maintain a healthy lifestyle, being informed about contraception, alcohol, drugs and smoking. Professionals in the team should be aware of the changing nature of children's educational needs as they grow older and should be skilled enough to adjust the level of the delivery of this appropriately. Specific training in adolescent medicine and resources on the subject are readily available in the UK, so teams should be equipped to provide the necessary education to young people who are progressing towards adulthood. ${ }^{45}$

\section{Insulin regimens}

An analysis of the different types of insulin available is not the aim of this review, but all consensus guidelines recommend that intensive insulin treatment, including pump therapy, should be provided by all centres treating children and young people, based on evidence extrapolated from the DCCT. ${ }^{14}$ This can only be provided effectively if the model of care can also deliver intensive education and communication support.

\section{Transition}

Transition is a "purposeful, planned process that addresses the medical, psychosocial and educational/vocational needs of adolescents and young adults with chronic physical and medical conditions as they move from childcentred to adult-oriented health care systems'. ${ }^{46}$

All the consensus guidelines stress the importance of transition and make a number of recommendations for delivery of care at this stage. Guidance documents specifically focused on transition have been produced by the Royal College of Physicians of Edinburgh ${ }^{45}$ and the Department of Health. ${ }^{47}$ The essence of these is that a smooth planned transition is necessary, with enough time for the young person to familiarise themselves with the practicalities of the move from paediatric towards adult services. The paediatric and adult teams should work together to provide seamless transition as it reduces the number of young people who are lost to follow-up.

Transition should occur at a time of relative stability in the individual's health and should be at a time agreed by the patient. At this stage in a young person's life glycaemic control deteriorates ${ }^{3}$ so it is important to ensure that they are engaged and actively involved in the transition process. The emphasis on transition has come about from the realisation that young people with diabetes are often unsatisfied with the care they receive from the diabetes care teams around the time they reach young adulthood. They express this by not attending clinics and not engaging with the services. ${ }^{48,49}$ Patient preference becomes a particularly important part of the model of care for young people at this stage.

Innovative strategies that depart from traditional methods of consultation, such as motivational interviewing (see below), may be more useful in this age group to maintain their engagement. Although there is now an increased effort to improve the transition process, there is little evidence to support what models work best at this time of life. An assumption that trying to improve clinic attendance will improve outcomes may not actually be true, and alternative options need to be examined. ${ }^{50}$

\section{SELF-MANAGEMENT SUPPORT}

This element of the CCM covers empowering and preparing patients to manage their health and healthcare.

\section{Collaborative management in chronic illness}

The consensus guidelines stress the need for diabetes teams to consider the child or young person and their parents as members of the team. This derives from the concept of collaborative management. Collaborative management occurs when patients and care providers have shared goals, a sustained working relationship, mutual understanding of roles and responsibilities and requisite skills for carrying out their roles. ${ }^{51}$ This means a move away 
The best model of care for children and young people

from consultations in which the professional defines the problem, prescribes a treatment and expects the patient to comply, towards the problem being defined by the patient and specific targets and goals set to aim for. This way of management does not assume that the patient will go away and sort out their problems themselves; rather it assumes a high level of contact with the patient, which may be by telephone, email or scheduled return visits.

A particular form of counselling which involves these processes is motivational interviewing. ${ }^{52}$ This has been trialled with promising results in a study in young people with diabetes in Wales. ${ }^{53}$ Counselling happened outside the clinic setting and did not specifically focus on diabetes targets, but recipients benefited, with improved $\mathrm{HbA}_{\mathrm{Ic}}$ and improved quality of life. It appears likely that incorporating this style of interviewing into the diabetes consultation will have a beneficial effect on the quality of care and may be more likely to lead to behaviour change. The current DEPICTED study from Cardiff University will provide more evidence of this in the near future. Recently the study group reported that among paediatric diabetes professionals significant deficiencies exist in training and experience in communication skills. ${ }^{54}$ This suggests that children and young people's psychosocial issues are not being attended to and this may significantly impair their ability to manage their own diabetes. Clearly this is an aspect of paediatric diabetes care that now needs to be the focus of more attention. The team psychologist should be in a position to co-ordinate the team's management of psychosocial issues with education and training of the team as well as the recommended role in screening for mental health issues..$^{2,29}$

Collaboration not only in the decision-making process about their diabetes care but also in the design of their diabetes service is now recognised as being very important for young people in order to keep them engaged and reduce their high rates of long-term complications. .,6,45,47 $^{-1}$

\section{Telephone support and new technologies}

To be effective, educational and motivational interventions need to be ongoing, with frequent telephone contact, and both face-to-face care and telephone availability have been demonstrated to improve $\mathrm{HbA}_{\mathrm{lc}}$ and to decrease hospitalisation rates for acute diabetes complications. ${ }^{22,23}$ Another variation in communication which has been proven to be beneficial is text messaging as a motivational tool. ${ }^{55}$ As more and more people make regular use of the internet it makes sense to explore this modality as a means of communicating with patients. A pilot study of a virtual diabetes clinic has been carried out in Warwick, UK. ${ }^{56}$ The participants were all adults with insulin pumps. Although there were no significant changes to $\mathrm{HbA}_{\mathrm{c}}$, the clinic was well accepted. Young people have shown positive attitudes to this type of clinic. ${ }^{57}$ Future research in this area is expected.

\section{COMMUNITY RESOURCES}

This element of the CCM covers the mobilisation of community resources to meet the needs of patients.

\section{Charities and patient support groups}

There are a number of community organisations which exist to support children and their families with diabetes, such as Diabetes UK and the Juvenile Diabetes Research Foundation. There is sparse evidence of effect in this area in childhood diabetes, although interestingly an audit of diabetes care and outcomes in Northern Ireland among children and young people found that membership of Diabetes UK was associated with lower $\mathrm{HbA}_{\mathrm{lc}}$ levels. ${ }^{58}$ Diabetes teams should be aware of the local and national community resources that exist to support families, as they may fill gaps in support provided by the health service. One example is diabetes camps, which are a recommended part of a child's experience, according to the Australian guidelines. ${ }^{27}$ This service may only be provided by charitable organisations in some countries.

\section{School support}

Children and young people spend most of their waking lives in school so it makes sense that personnel there should be trained to provide or supervise all diabetes care prescribed by the diabetes team. The local diabetes team should be responsible for establishing this. ${ }^{2,22,27,59}$

\section{HEALTHCARE ORGANISATION}

This element of the CCM covers support from all levels of the organisation and includes strategies for comprehensive system change.

Healthcare systems for childhood diabetes require support and backing from government and senior management. In the UK, government directives are in place which local healthcare organisations are expected to implement.These are the National Service Frameworks (NSFs). ${ }^{60-63}$ The main roles of NSFs are to set clear quality requirements for care based on the best available evidence, and to offer strategies and support to help health organisations achieve these standards. ${ }^{64}$

The NSFs for diabetes incorporate standards which are based on the SIGN guidelines (Scotland) ${ }^{29}$ and NICE guidelines (England and Wales) ${ }^{2}$. As with any government directive, the ability of the NSFs to improve the quality of care relies on them being implemented efficiently and monitored. The national diabetes audit is used in England and Wales to monitor several processes of care for the NSF, but less than $40 \%$ of centres in England submit data for this due to lack of time and resources. ${ }^{4}$ Despite the standard-setting exercises of the NSFs in the UK, there remain obstacles to achieving them. The five-year report on the NSF in England has revealed deficiencies. ${ }^{65} \mathrm{~A}$ recent survey of nursing practice in the UK found that 
SWilliamson

although numbers of specialist nurses had increased, the mean ratio of nurses to patients was I:109,66 well below the recommendation of $1: 70,{ }^{34}$ and a survey of services in 2002 in the UK found that most clinics had very limited access to psychology services and inadequate dietetic resources. ${ }^{32}$ These findings suggest that without strong incentives or increased financial resources, local health services will not automatically implement these standards in the UK.

The answer to this problem may lie in the creation of regional managed clinical networks. This has been proposed in England by the Department of Health working group responsible for the recent document Making every young person with diabetes matter. ${ }^{67}$ The proposal suggests that regional networks would support strategic development, would be responsible for quality assurance and audit, and would support local services in their provision of aspects such as pump services, education or out-of-hours support. In Scotland the equivalent would be a national managed clinical network (MCN) for children's diabetes services. With these powers a single MCN would be best placed to ensure that consistent high-quality care is delivered with equity of resources and equal care across the nation.

\section{CLINICAL INFORMATION SYSTEMS}

This element covers organising patient and population data to facilitate efficient and effective care.

\section{Evaluating healthcare}

Clearly we need to assess the way healthcare is delivered for children with diabetes to add to the many experimental studies of their treatments. Treatments are usually assessed by their effect on outcomes. However, to assess the quality of healthcare we should look mainly at processes; ${ }^{68}$ that is, if a standard is set for the process, such as 'all children over 12 years should be screened for retinopathy annually', then is that actually being carried out? If it is not, then we cannot expect the outcomes to improve. A change in the structure (e.g. an increase in clinic personnel) may be necessary to allow the process to happen.

The CCM is designed to allow healthcare providers to consider in detail the structural factors and how they affect the process, and to focus on them as a means to improve their model of care. Arguably, audit then becomes the most important aspect of the CCM because it underpins the whole process of improvement. If good quality audit and monitoring is in place, then robust data on structures, processes and outcomes will be available and the model of care can improve using feedback on its own performance. The importance of audit and monitoring outcomes in patients with diabetes was established in 1989 after a meeting of the World Health Organization and International Diabetes
Federation in Italy (the StVincent declaration). ${ }^{12}$ National audits of children's diabetes services and outcomes have revealed important data in the past, but in Scotland this has not been an ongoing audit., ${ }^{3,17}$ To be fully effective it should be carried out continuously, be co-ordinated by a national body (for example, Paediatric Diabetes MCN) and be fully supported financially by the government.

\section{IT systems and databases}

Clinical databases are a necessity for effective audit and should be used in the care of children with diabetes, both at local and regional or national levels. Their use for quality improvement purposes has been described in Denmark ${ }^{20,69}$ and Germany. ${ }^{33}$ In England and Wales there is not a universal database for the monitoring of standards nationally and this means the national diabetes audit is incomplete. ${ }^{4}$ The national diabetes framework in Scotland aims to implement the Scottish Care Information - Diabetes Collaboration computer database nationally. ${ }^{70}$ As yet, this system has not produced any robust data on childhood diabetes care in Scotland, but it has the potential for this.

\section{FUTURE WORK AIMED AT FINDING THE BEST MODEL OF CARE}

The international SWEET project attempts to follow on from the Hvidøre group to investigate the factors that in practice allow some centres to have better outcomes than others. This is an international European study which aims to define centres of reference for paediatric and adolescent diabetes in order to produce recommendations for minimum treatment and care, patient education programmes and training programmes for health professionals. ${ }^{71}$ It is likely to be several years before results are available.

The Diabetes Attitudes, Wishes and Needs (DAWN) youth project is an initiative by Novo Nordisk, ISPAD and the International Diabetes Federation. It has five key goals: improved communication between patients and healthcare professionals, improved team care and collaboration between professionals, improved support for self-management, overcoming psychosocial barriers to the use of effective therapies and providing psychological support. It recognises that these factors have a significant effect on the outcomes of children with diabetes and aims to address the deficiencies through research, education and training. ${ }^{72}$

\section{CONCLUSION}

The best model of care for children and young people has at its centre a well-resourced multidisciplinary team which is able to have frequent clinical contact with its patients and is available for them 24 hours a day. It is able to carry out screening and educational interventions and to co-ordinate transition to the nationally set standards. The team continually evaluates its performance in 
carrying out evidence-based processes, and strives towards improved outcomes. It has access to and uses IT facilities to help it achieve this. The team is aware of the resources available for its patients in the wider community and helps them use these. Underpinning all of these factors is the team's approach to the child and parents; the team accepts the child and parents they are caring for as part of the team and aims to help them care for themselves with motivational tools and education, focusing on treatment goals and good communication. In order to ensure that all children and young people across the country can have access to the same highquality care, the local service must be resourced and supervised by a central organisation such as a specific managed clinical network.

\section{REFERENCES}

I Patterson CC, Dahlquist GG, Gyürüs E et al. Incidence trends for childhood type I diabetes in Europe during 1989-2003 and predicted new cases 2005-20: a multicentre prospective registration study. Lancet 2009; 373:2027-33. doi:10.1016/SOI406736(09)60568-7

2 National Institute for Health and Clinical Excellence. Type I diabetes: diagnosis and management of type I diabetes in children and young people. London: NICE; 2004.

3 Scottish Study Group for the Care of the Young with Diabetes. A longitudinal observational study of insulin therapy and glycaemic control in Scottish children with type I diabetes: DIABAUD 3. Diabet Med 2006; 23:1216-21. doi:10.1III/j.1464-549I.2006.01962.x

4 The Information Centre for Health and Social Care. National diabetes audit: key findings about the quality of care for children and young people with diabetes in England and Wales: report for the audit period 2007-2008. London: NHS; 2008.

5 Laing SP, Swerdlow AJ, Slater SD et al. The British Diabetic Association Cohort Study, I: all-cause mortality in patients with insulin-treated diabetes mellitus. Diabet Med 1999; 16:459-65. doi:10.1046/j. I 164-549I.1999.00075.x

6 Bryden KS, Peveler RC, Stein A et al. Clinical and psychological course of diabetes from adolescence to young adulthood: a longitudinal cohort study. Diabetes Care 200I; 24:1536-40. doi:10.2337/diacare.24.9.1536

7 Northam EA, Matthews LK, Anderson PJ et al. Psychiatric morbidity and health outcome in type I diabetes - perspectives from a prospective longitudinal study. Diabet Med 2005; 22:152-7. doi:I0.1 III/j.1464-549I.2004.01370.x

8 Davidson P, Halcomb E, Hickman L et al. Beyond the rhetoric: what do we mean by a 'model of care'? Aust J Adv Nurs 2006; 23:47-55.

9 Queensland Health. Changing models of care framework. Brisbane: Queensland Health; 2000. Available from: http://www.health.qld. gov.au/publications/change_management/Care_Framework.pdf

10 Brook RH, McGlynn EA, Cleary PD. Quality of health care. Part 2: measuring quality of care. N Engl J Med 1996; 335:966-70. doi:I0.1056/NEJMI9960926335I3II

II Jefferson IG, Swift PG, Skinner TC et al. Diabetes services in the UK: third national survey confirms continuing deficiencies. Arch Dis Child 2003; 88:53-6. doi:10.1 I36/adc.88.1.53

12 Diabetes care and research in Europe: the Saint Vincent declaration. Diabet Med 1990; 7:360. doi:I0.IIII/j.I464-549I.1990.tb0I405.x

13 British Paediatric Association Working Party. The organisation of services for children with diabetes in the United Kingdom: report of the British Paediatric Association Working Party. Diabet Med 1990; 7:457-64. doi:I0.IIII/j.I464-549I.1990.tb0|423.x

14 The Diabetes Control and Complications Trial Research Group. The effect of intensive treatment of diabetes on the development and progression of long-term complications in insulin-dependent diabetes mellitus. N Engl J Med 1993; 329:977-86. doi:10.1056/ NEJMI9930930329140I

15 Mortensen HB, Hougaard P. Comparison of metabolic control in a cross-sectional study of 2,873 children and adolescents with IDDM from 18 countries. The Hvidøre Study Group on Childhood Diabetes. Diabetes Care 1997; 20:714-20. doi:10.2337| diacare.20.5.714
16 Danne T, Mortensen HB, Hougaard P et al. Persistent differences among centers over 3 years in glycemic control and hypoglycemia in a study of 3,805 children and adolescents with type I diabetes from the Hvidøre Study Group. Diabetes Care 200I; 24:1342-7. doi:10.2337/diacare.24.8.1342

17 Diabetic Scottish Study Group for the Care of the Young. Factors influencing glycemic control in young people with type I diabetes in Scotland: a population-based study (DIABAUD2). Diabetes Care 200I; 24:239. doi: 10.2337/diacare.24.2.239

18 Greene AC, Tripaldi M, Chiarelli F et al. Cross-cultural differences in the management of children and adolescents with diabetes. Horm Res 2002; 57(Suppl I):75-7. doi:10.1 I59/000053319

19 Bulsara MK, Holman CD, Davis EA et al. The impact of a decade of changing treatment on rates of severe hypoglycemia in a population-based cohort of children with type I diabetes. Diabetes Care 2004; 27:2293-8. doi:I0.2337/diacare.27.10.2293

20 Svensson J, Johannesen J, Mortensen HB et al. Improved metabolic outcome in a Danish diabetic paediatric population aged 0-18 yr: results from a nationwide continuous registration. Pediatr Diabetes 2009; 10:46 I-7. doi:I0. I I I I/j. I399-5448.2008.00460.x

21 Wagner EH, Austin BT, Davis C et al. Improving chronic illness care: translating evidence into action. Health Aff 200I; 20:64-78. doi:I0.1377/hlthaff.20.6.64

22 Pihoker C, Forsander G, Wolfsdorf J et al. The delivery of ambulatory diabetes care: structures, processes, and outcomes of ambulatory diabetes care. Pediatr Diabetes 2008; 9:609-20. doi:I0.I I I I/j. I399-5448.2008.00480.x

23 Silverstein J, Klingensmith G, Copeland K et al. Care of children and adolescents with type I diabetes. Diabetes Care 2005; 28:186212. doi:10.2337/diacare.28.1.186

24 Wagner EH. Chronic disease management: what will it take to improve care for chronic illness? Effective Clin Pract 1998; I:2-4.

25 Pearson ML, Wu S, Schaefer J et al. Assessing the implementation of the chronic care model in quality improvement collaboratives. Health Serv Res 2005; 40:978-96. doi:I0.I I II/j.I475-6773.2005.00397.x

26 World Health Organization. Innovative care for chronic conditions: building blocks for action. Geneva:WHO; 2002.

27 Australasian Paediatric Endocrine Group. Clinical practice guidelines: type I diabetes in children and adolescents. Canberra: National Health and Medical Research Council; 2005.

28 American Diabetes Association. Standards of medical care in diabetes - 2009. Diabetes Care 2009; 32(Suppl I):SI3-S6I. doi: $10.2337 / \mathrm{dc09}-\mathrm{SO} / 3$

29 Scottish Intercollegiate Guidelines Network. Management of diabetes: a national clinical guideline (guideline II6). Edinburgh: SIGN; 2010.

30 Canadian Diabetes Association Clinical Practice Guidelines Expert Committee. Clinical practice guidelines for the prevention and management of diabetes in Canada. Can J Diabetes 2008; 32 (Suppl I):SI50-SI6I.

3I Baumer JH, Hunt LP, Shield JP. Audit of diabetes care by caseload. Arch Dis Child 1997; 77: 102-7. doi:10.1136/adc.77.2.102

32 Edge JA, Swift PG, Anderson W et al. Diabetes services in the UK: fourth national survey; are we meeting NSF standards and NICE guidelines? Arch Dis Child 2005; 90:1005-9. doi:10.1136/ adc.2005.07/6I3 
SWilliamson

33 Gerstl EM, RabIW, Rosenbauer J et al. Metabolic control as reflected by $\mathrm{HbAlc}$ in children, adolescents and young adults with type-I diabetes mellitus: combined longitudinal analysis including 27,035 patients from 207 centers in Germany and Austria during the last decade. Eur J Pediatr 2008; 167:447-53. doi:10.1007/s00431-007-0586-9

34 Royal College of Nursing Paediatric and Adolescent Group. Specialist nursing services for children and young people with diabetes. London: RCN; 2006.

35 Smart C, Aslander-van Vliet E, Waldron S. Nutritional management in children and adolescents with diabetes. Pediatr Diabetes 2009; I0(Suppl I2): I00-17. doi:I0.I I I I/j.I399-5448.2009.00572.x

36 Clar C, Waugh N, Thomas S. Routine hospital admission versus out-patient or home care in children at diagnosis of type I diabetes mellitus. Cochrane Database Syst Rev 2009; 3:CD004099.

37 Jacobson AM, Hauser ST,Willett J et al. Consequences of irregular versus continuous medical follow-up in children and adolescents with insulin-dependent diabetes mellitus. J Pediatr 1997; | $31: 727-$ 33. doi:I0.10I6/S0022-3476(97)70I0I-X

38 Kaufman FR, Halvorson M, Carpenter S. Association between diabetes control and visits to a multidisciplinary pediatric diabetes clinic. Pediatrics 1999; 103:948-5I. doi:10.1542/peds. 103.5 .948

39 Laffel LM, Brackett J, Ho J et al. Changing the process of diabetes care improves metabolic outcomes and reduces hospitalizations. Qual Manag Health Care 1998; 6:53-62.

40 National Institute for Health and Clinical Excellence. Type I diabetes in children and young people. London: NICE; 2009. Available from: http://www.nice.org.uk/nicemedia/live/I0944/29399/29399.pdf

4I DAFNE Study Group. Training in flexible, intensive insulin management to enable dietary freedom in people with type I diabetes: dose adjustment for normal eating (DAFNE) randomized controlled trial. Diabet Med 2003; 20(Suppl 3):4-5 doi: I0.I034/j. I600-6I43.2003.000987_3.x

42 Ulahannan TJ, Ross W, Davies FC. Carbohydrate counting in type I diabetes: time to REACCT. Pract Diabetes Int 2007; 24:134-6. doi: 10.1002/pdi. 1077

43 Lowe J, Linjawi S, Mensch M et al. Flexible eating and flexible insulin dosing in patients with diabetes: results of an intensive selfmanagement course. Diabetes Res Clin Pract 2008; 80:439-43. doi:10.1016/j.diabres.2008.02.003

44 Waller H, Eiser C, Knowles J et al. Pilot study of a novel educational programme for II-16 year olds with type I diabetes mellitus: the KICk-OFF course. Arch Dis Child 2008; 93:927-3I. doi:I0.II36/ adc.2007.132126

45 Royal College of Physicians of Edinburgh Transition Steering Group. Think transition: developing the essential link between paediatric and adult care. Edinburgh: RCPE; 2008.

46 Blum RW, Garell D, Hodgman $\mathrm{CH}$ et al. Transition from childcentered to adult health-care systems for adolescents with chronic conditions: a position paper of the Society for Adolescent Medicine. J Adolesc Health 1993; 14:570-6. doi:10.1016/1054I39X(93)90|43-D

47 Department of Health/Child Health and Maternity Services Branch. Transition: getting it right for young people. London: $\mathrm{DOH} ; 2006$.

48 Kipps S, Bahu T, Ong K et al. Current methods of transfer of young people with type I diabetes to adult services. Diabet Med 2002; | 9:649-54. doi:I0.| 046/j. | 464-549|.2002.00757.x

49 Channon S, Smith V, Alcolado J et al. Current methods of transfer of young people with type I diabetes to adult services. Diabet Med 2003; 20:1034. doi:10.1III/j. |464-549|.2003.009|9.x

50 Allen D, Gregory J. The transition from children's to adult diabetes services: understanding the 'problem'. Diabet Med 2009; 26:162-6. doi:I0. I I I I/j.|464-549|.2008.02647.x
5I Von Korff M, Gruman J, Schaefer J et al. Collaborative management of chronic illness. Ann Intern Med 1997; 127:1097-102.

52 Miller WR, Rollnick S. Motivational interviewing: preparing people for change. New York: Guilford Press; 2002.

53 Channon SJ, Huws-Thomas MV, Rollnick S et al. A multicenter randomized controlled trial of motivational interviewing in teenagers with diabetes. Diabetes Care 2007;30: I390-5. doi: I0.2337/ dc06-2260

54 Hambly H, Robling M, Crowne E et al., for the DEPICTED Study Team. Communication skills of healthcare professionals in paediatric diabetes services. Diabet Med 2009; 26:502-9. doi:I0.IIII/j.|464-549I.2009.02708.x

55 Franklin VL, Waller A, Pagliari C et al. "Sweet Talk": text messaging to support intensive insulin therapy. Arch Dis Child 2005; 90(Suppl 2):AIO.

56 Jennings $A$, Powell J, Armstrong $\mathrm{N}$ et al. A virtual clinic for diabetes self-management: pilot study.J Med Internet Res 2009; I I:el0.

57 Lowe P, Hearnshaw H, Griffiths F. Attitudes of young people with diabetes to an internet-based virtual clinic. J Telemed Telecare 2005; I I (Suppl I):59-60. doi: I 0.1258/I35763305446/840

58 Cardwell CR, Patterson CC,Allen M et al. Diabetes care provision and glycaemic control in Northern Ireland: a UK regional audit. Arch Dis Child 2005; 90:468-73. doi:I0.II36/adc.2004.06II50

59 American Diabetes Association. Diabetes care in the school and day care setting. Diabetes Care 2008; 3I(Suppl I):S79-86. doi: $10.2337 / \mathrm{dc} 08-5079$

60 Clinical Standards Board for Scotland. Scottish diabetes framework. Edinburgh: Scottish Government; 2002. Available from: http://www scotland.gov.uk/Publications/2002/04/I4452/1983

61 Department of Health. Diabetes National Service Framework London: DOH; 200I. Available from: http://www.diabetes.nhs.uk/ national service framework/

62 National Service Frameworks for Wales. Diabetes NSF. Cardiff: Welsh Assembly Government; 2002. Available from: http://www. wales.nhs.uk/sites3/home.cfm?orgid=440

63 Clinical Resource Efficiency Support Team. Executive summary of the report of the Northern Ireland Task Force on Diabetes. Belfast: CREST; 2003. Available from: http://www.gain-ni.org/guidelines/diabetessummary.pd1

64 National Strategies Overview. Available from: http://www.nhs.uk/ nhsengland/nsf/pages/nationalserviceframeworks.aspx

65 Department of Health. Five years on: delivering the Diabetes National Service Framework. London: DOH; 2008.

66 James J, Gosden C, Winocour P et al. Diabetes specialist nurses and role evolvement: a survey by Diabetes UK and ABCD of specialist diabetes services 2007. Diabet Med 2009; 26:560-5. doi: I0.I I I I/j.|464-549I.2009.027|6.x

67 Department of Health Diabetes Policy Team. Making every young person with diabetes matter. London: DOH; 2007.

68 Brook RH, McGlynn EA, Shekelle PG. Defining and measuring quality of care: a perspective from US researchers. Int J Qual Health Care 2000; 12:281.

69 Nordly S, Mortensen HB,Andreasen AH et al. Factors associated with glycaemic outcome of childhood diabetes care in Denmark. Diabet Med 2005; 22: I566-73. doi: I0. I I I I/j. I464-549I.2005.01692.x

70. Scottish Executive. Scottish diabetes framework action plan. Edinburgh: Scottish Executive; 2006.

7I SWEET Project: http://sweet-project.eu/html/en/index_html

72 Aanstoot H. DAWN Youth: a direct response to young people's attitudes, wishes, and needs. Pediatr Diabetes 2009; 10:15-20. doi: I0.1 I I I/j.I399-5448.2009.006 I0.x 